\title{
Components of Reading Ability: Multivariate Evidence for a Convergent Skills Model of Reading Development
}

\author{
Frank R. Vellutino \\ The University at Albany \\ William E. Tunmer \\ Massey University \\ James J. Jaccard \\ Florida International University \\ RuSan Chen \\ Georgetown University
}

\begin{abstract}
Elementary and middle school children were given a large battery of tests evaluating reading subskills and reading-related cognitive abilities. These measures were used to define latent constructs representing skills and abilities believed to be important components of reading comprehension. Hypothesized relationships among these constructs were specified within the context of a structural model we call the "Convergent Skills Model of Reading Development," and developmental differences in the relative contribution made by each construct to reading comprehension performance were assessed through confirmatory factor analysis using the LISREL and AMOS programs. Results provide qualified support for the model and were interpreted as consistent with the major premises of both Gough and Tunmer's (1986) "Simple View" and Sticht's (1979) "Audread" models of reading.
\end{abstract}

Because written English is an alphabetic orthography and because of the high degree of redundancy characteristic of any alphabetic orthography, the load on visual memory in print processing is extraordinary. Thus to reduce this load to manageable pro-

Correspondence should be sent to Frank R. Vellutino, Child Research and Study Center, The University at Albany, 1535 Western Avenue, Albany, NY 12203.E-mail: frv@csc.albany.edu 
portions, fledging readers must acquire explicit knowledge and functional use of the alphabetic code. To ultimately acquire adequate facility in word identification, they must come to detect and represent the structurally redundant and invariant properties of the orthography. Accordingly, many researchers suggest that visual analysis of printed words is mediated by the language systems in learning to read, especially by the phonological system (e.g., Gough \& Tunmer, 1986; Liberman \& Liberman, 1990; Liberman \& Shankweiler, 1979; Share, 1995; Vellutino, Scanlon, \& Chen, 1995). It follows that phonological skills such as phoneme segmentation and phonological (letter-sound) decoding would carry greater weight as determinants of success in beginning reading than would visual skills, but as children acquire a high degree of proficiency in word identification and other word-level skills, language comprehension and the underlying oral language processes would likely become the primary sources of variability in reading because individual differences in word identification and phonological decoding diminish as a source of such variability. In addition, the more diverse and more advanced reading materials to which developing readers are increasingly exposed tend to make greater demands on higher level language skills (e.g., vocabulary and syntactic knowledge).

This hypothesized asymmetry in the relative contributions made by reading subskills and related cognitive abilities at given stages of reading acquisition is a central feature of both Sticht's (1979) "Audread" and Gough and Tunmer's (1986) "Simple View" models of reading. Initial support for these models came from studies of both children (Curtis, 1980; Hoover \& Gough, 1990; Vellutino, Scanlon, Small, \& Tanzman, 1991; Vellutino, Scanlon, \& Tanzman, 1994) and adults (Sticht, 1979), in which it was found that tests of context-free word identification and/or phonological decoding were much better predictors of performance on tests of reading comprehension in participants having limited skill in reading than in participants having more advanced skill in reading. In contrast, tests of language comprehension were much better predictors of performance on tests of reading comprehension in participants having more advanced skill in reading than in participants having limited skill in reading (see also Goff, Pratt, \& Ong, 2005; Seigneuric \& Ehrlich, 2005). It was also found in these studies that reading and listening comprehension were rather disparate in the least skilled readers but concordant in the more advanced readers. Both sets of findings suggest that language comprehension processes do not become fully operative in reading until the reader has acquired enough facility in word identification to comprehend, in written language, text that would normally be comprehended in spoken language.

The preeminence of phonological skills as determinants of success in beginning reading has been firmly established through training and intervention studies documenting a causal relationship between these skills and reading achievement as well as by correlation studies documenting that they are good predictors of reading performance and reliably discriminate between poor and normal readers (e.g., Blachman, 2000; Bradley \& Bryant, 1983; Iversen \& Tunmer, 1993; Torgesen, 
Wagner, \& Rashotte, 1999; Tunmer, 1989; Vellutino, Fletcher, Snowling, \& Scanlon, 2004; Vellutino \& Scanlon, 1987a, 1987b; Vellutino et al., 1996; Wagner $\&$ Torgesen, 1987). That the visual system is subordinated by the language systems in learning to read is given tentative support by numerous studies showing no reliable differences between poor and normal readers on tests of visual processing abilities (e.g., Vellutino, 1979; Vellutino et al., 2004; Vellutino \& Scanlon, 1987a, 1987b). Yet, the relative contributions made by phonological and visual skills as well as by higher level language skills to reading development have not been extensively evaluated. Thus the primary purpose of this study was to test a theoretical model of hypothesized causal relationships among the major skills and abilities underlying context-free word identification and language comprehension, the two proximal causes of reading comprehension. A secondary purpose was to assess developmental changes in the structure of the (hypothesized) causal relationships specified by the model. Although previous studies have provided piecemeal evidence for many of these relationships (e.g., the relationship between phonological awareness and phonological decoding or between word identification and reading comprehension), few have assessed such relationships within the context of a comprehensive structural model such as the Convergent Skills Model (e.g., Lonigan, Burgess, \& Anthony, 2000; Storch \& Whitehurst, 2002; Tunmer \& Chapman, 2006), and none have assessed the viability of the particular configuration of theoretical relationships specified by our model. Further, whereas previous studies have documented asymmetry in the relative contributions made by context-free word identification and language comprehension to reading comprehension in individuals at different levels of reading development (e.g., Hoover \& Gough, 1990; Sticht, 1979), none, to our knowledge, have attempted to replicate this developmental asymmetry within the context of a theoretical model that also specifies interrelationships among the major cognitive skills and abilities believed to underlie these components of reading ability. Moreover, none have compared parameter estimates reflecting these relationships at different levels of reading development. This study does both.

\section{THE CONVERGENT SKILLS MODEL OF READING DEVELOPMENT}

The theoretical model is presented in Figure 1. The model depicts hypothesized relationships among latent constructs defining reading subskills and certain cognitive abilities presumed to underlie those subskills (latent constructs are henceforth capitalized). To the far right are endogenous (dependent) latent constructs that define the three major components of reading ability: (a) Reading Comprehension, herein defined as the ability to comprehend written language; (b) Context-Free Word Identification, the ability to identify printed words without the aid of context; 


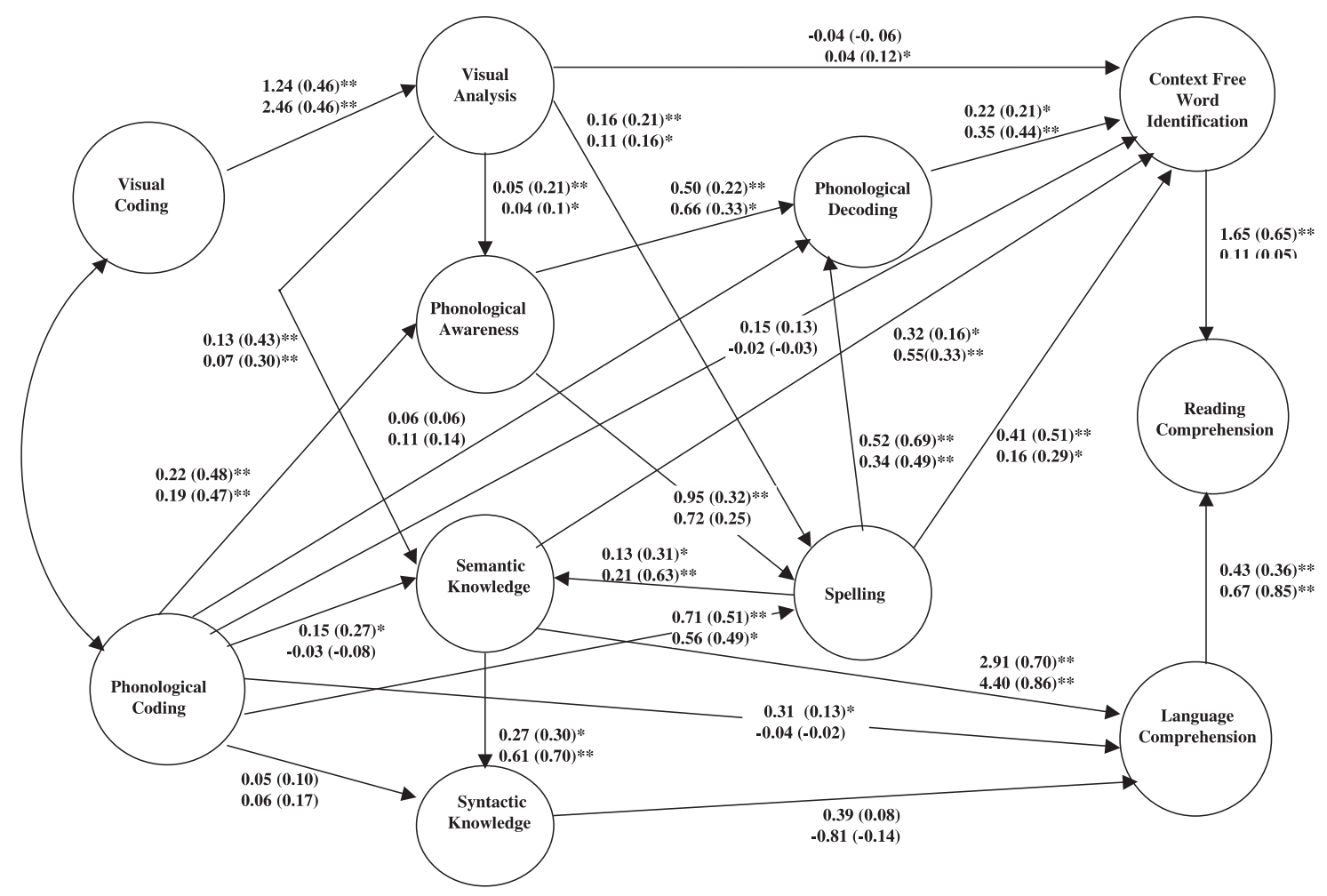

FIGURE 1 Convergent skills model of reading development: Younger/Older groups. Note: Coefficients for the Younger group are always listed above those for the Older group. Standard coefficients are in parentheses. ${ }^{*} p \leq .05 .{ }^{* *} p \leq .01$. 
and (c) Language Comprehension, the ability to comprehend spoken language. To the far left are exogenous (independent) latent constructs defining Phonological Coding ability and Visual Coding ability. Given that learning to read in alphabetically based orthographies entails visual recoding of language in the form of alphabetic characters representing speech segments, and given that both Phonological and Visual Coding are involved to some extent in language acquisition and language processing, we suggest that these two abilities are among the most basic of the various cognitive abilities that underlie the ability to learn to read.

Phonological Coding is defined as the ability to use speech-coding mechanisms to encode (represent) information linguistically. It aids in storing and retrieving linguistic units (e.g., phonemes, morphemes, sentences), in analyzing and synthesizing these units, and in establishing connective bonds between them and the entities they represent. Thus in addition to its demonstrated importance in vocabulary acquisition (Gathercole \& Baddeley, 1989, 1990)_depicted in Figure 1 through direct links to the semantic component of the model—Phonological Coding is presumed to be critically important to success in learning to read by virtue of the direct and indirect contributions it makes to the acquisition of facility in speech segmentation (Phonological Awareness), alphabetic mapping (Phonological Decoding), spelling and writing (Spelling), and word identification (Context-Free Word Identification). Similarly, there is both theoretical and empirical evidence that comprehension of spoken language depends, in some measure, on one's ability to use speech-coding mechanisms to hold linguistic units in working memory, prior to assembling them into meaningful propositions (Baddeley, 1986; Goff et al., 2005; Seigneuric \& Ehrlich, 2005). Thus Phonological Coding is assumed to have a significant influence on both syntactic processing and general language comprehension, as indicated by direct links from this construct to Syntactic Knowledge and Language Comprehension, respectively.

Visual Coding is defined as the ability to encode, store, and retrieve visual information. Its ultimate contribution to reading development is to facilitate visual word recognition, but because of the constraints on visual memory imposed by an alphabetic writing system, we assume that Visual Coding is mediated, in part, by an analytic process we call Visual Analysis. Visual Analysis aids memory by facilitating attention to visual detail and detection of visual patterns. It facilitates reading development primarily by virtue of the contribution it makes to letter and word discrimination, to the detection and encoding of redundant spelling patterns (e.g., at in cat, fat, hat), and to the learning of letter-sound relationships. However, given the likelihood that the learning of letter-sound relationships comes primarily through one's experience in discriminating, identifying, and spelling written words, Visual Analysis is hypothesized to contribute directly to Context-Free Word Identification and Spelling but only indirectly to Phonological Decoding. Finally, we assume that Visual Analysis mediates the relationship between Visual Coding and Semantic Knowledge. 
Phonological Awareness is defined as explicit awareness and conceptual grasp of the idea that spoken words consist of speech segments. We assume, along with others (e.g., Blachman, 2000; Bradley \& Bryant, 1983; Liberman \& Liberman, 1990; Liberman \& Shankweiler, 1979; Wagner \& Torgesen, 1987), that Phonological Awareness and at least rudimentary facility in phoneme segmentation are basic prerequisites for success in beginning reading, because it is in learning to segment speech that the child begins to concretize and make functional use of the alphabetic principle. Thus Phonological Awareness is presumed to influence the acquisition of skill in reading by virtue of the direct effects it has on Spelling and Phonological Decoding and the indirect effects it has on Context-Free Word Identification.

In the present context, Semantic Knowledge is defined as vocabulary knowledge and verbal concept development. Syntactic Knowledge is defined as implicit knowledge of grammatical rules for ordering, coreferencing, and inflecting the words in sentences (Tunmer, Nesdale, \& Wright, 1987). Both types of knowledge are presumed to contribute directly to Language Comprehension. Given the importance of vocabulary knowledge and verbal concept development in sentence comprehension, Semantic Knowledge is also presumed to contribute directly to the acquisition of Syntactic Knowledge. Because acquiring facility in word identification depends, in part, on the child's knowledge of the meanings of the words he or she is learning to identify, Semantic Knowledge is also presumed to contribute directly to Context-Free Word Identification.

Between the basic cognitive abilities underlying reading ability and the three major components of reading ability are Spelling and Phonological Decoding. Spelling is the productive ordering of the letters that specifically define a word. Phonological Decoding is the ability to map alphabetic characters to sound and thus to use letter-sound analysis as a vehicle for identifying printed words. Both are presumed to have direct effects on Context-Free Word Identification. The direct effects of Phonological Decoding inhere in the child's growing ability to use the alphabetic code to "sound out" printed words that are not immediately identified. The direct effects of Spelling inhere in the potential it holds for fostering structural analysis of the type that facilitates precision in encoding the letters in printed words, the order in which they occur, and word-specific spellings in general. Spelling is also presumed to have a direct effect on Phonological Decoding because it is, in part, through early experience in using letter sounds to aid Spelling that the child begins to acquire functional use of the alphabetic code and becomes increasingly familiar with the orthographic and morphological regularities and irregularities inherent in written English (Ehri, 1991; Frith, 1985). Because academic learning provides the child with many opportunities to increase vocabulary knowledge through spelling and writing (e.g., learning to spell homophones such as pane and pain or related words such as compete and competition, etc.), we assume that Spelling also makes a direct contribution to the semantic component of language (see Henderson, 1990, and Templeton, 1995, for similar views). 
Finally, Context-Free Word Identification and Language Comprehension are both presumed to make direct and independent contributions to Reading Comprehension. In accord with the theoretical arguments presented earlier, we expected that Context-Free Word Identification, along with the phonological skills and abilities underling Context-Free Word Identification, would be more strongly related to Reading Comprehension in younger readers than in older, more advanced readers. Conversely, we expected that Language Comprehension and the semantic and syntactic abilities that underlie Language Comprehension would be more strongly related to Reading Comprehension in older, more advanced readers than in younger readers. We also expected that language-based skills, especially phonological skills, would mediate causal relationships between visual skills and reading ability, given the load on visual memory imposed by the alphabetic properties of written English.

\section{METHOD}

\section{Participants}

Participants were developing readers in Grades 2 and 3 combined (henceforth called "Younger") and Grades 6 and 7 combined (henceforth called "Older"). ${ }^{1}$ A total of 468 children participated in the study, 297 in the Younger group and 171 in the Older group $(n=166$ Grade $2 ; n=131$ Grade $3 ; n=133$ Grade $6 ; n=38$ Grade 7). All came from schools located in middle-class to upper middle-class neighborhoods in the Albany, New York, area, and all were selected on the basis of measures evaluating (a) oral reading of narrative text; (b) intelligence; and (c) the following exclusionary criteria: uncorrected sensory acuity problems; emotional, social, physical, and neurological problems; and frequent absences from school. The Gilmore Oral Reading Test, Form D (Gilmore \& Gilmore, 1968) was used to evaluate reading achievement, and the Wechsler Intelligence Scale for Children-Revised (WISC-R; Wechsler, 1974) was used to evaluate intelligence. Exclusionary criteria were evaluated through questionnaires completed by appropriate school personnel. There were four levels of reading ability within each grade stratification: severely impaired ( $n=66$ Younger, $n=45$ Older), moderately impaired ( $n=71$ Younger, $n=43$ Older), average ( $n=73$ Younger, $n=46$ Older), and good readers ( $n=87$ Younger, $n=37$ Older). Severely impaired readers scored at or below the 10th percentile on the oral reading test, moderately impaired readers scored between the 10th and 30th percentiles on the test, average readers scored

\footnotetext{
${ }^{1}$ The participants in this study were children in a larger study evaluating the etiology of reading disability. Preliminary results from this study are discussed by Vellutino et al. (1991) and Vellutino et al. (1994). Results reported in the article presented here are based on the final data set for the study.
} 
between the 40th and 60th percentiles, and good readers scored at or above the 75th percentile. All of these children had to have an IQ of 90 or above on either the Verbal or the Performance subscales of the WISC-R to be included in the sample. None had any problems in the areas defined by the exclusionary criteria outlined previously. Each participating school contributed participants to both the impaired and normal reader groups, and an effort was made to select comparable numbers of children from each ability stratum within a school. Because these children were selected from a large number of schools $(N=50)$, the possibility of sampling bias was minimized.

\section{Materials and Procedures}

For all the measures described next, maximum scores, means, standard deviations, and reliability coefficients are presented in Table 1 . All the maximum scores are raw scores reflecting the total number of correct responses summed across items and/or trials. Administration and scoring procedures for published tests were taken from the test manuals, as were reliability coefficients for those tests. Administration and scoring procedures for experimental tests are specified subsequently. Reliability estimates for experimental tests were calculated on randomly selected subsamples of participants from each age/grade group ( $n=30$ per group) using the odd-even method of computing internal consistency. Coefficients, in all instances, are based on Cronbach's alpha.

With the exception of Reading and Language Comprehension (for which only one test of each construct was available), all latent constructs were initially evaluated using at least two observed measures. However, because some of these measures produced disparate variability estimates in the Younger and Older groups, we were forced to select the measure of the construct that produced comparable estimates in the two groups. In cases in which latent constructs were defined by a single indicator, the error variance associated with a given measure was estimated from the reliability coefficient for that measure, and this estimate was used in all analyses evaluating true score variance and model fit (Jöreskog \& Sörbom, 1993b). In cases where reliability coefficients were relatively low, we conducted additional analyses in which error variances were set to zero (assuming perfect reliability), and in no instance did this procedure produce any substantial change in model fit (Jaccard \& Wan, 1996).

Note also that the standardized tests used to measure given latent constructs all have well-established validity as measures of those constructs. The experimental tests used to measure the remaining latent constructs were selected on the basis of their convergent and discriminant validity in terms of their relationships to other measures that have well-established construct and empirical validity. 


\section{Exogenous Latent Constructs}

Visual Coding. Visual Coding was evaluated using an experimental test of visual memory: memory for spatial locations. This test was found in previous research (Vellutino et al., 1996; Vellutino et al., 1994) to correlate significantly with other measures of visual-processing ability and more highly with these measures than with measures of language processing abilities (see also Table 1). It entailed memory for the spatial locations of dots forming individual visual patterns presented on a matrix consisting of either 9 or 12 cells. Each matrix was presented for $2 \mathrm{sec}$, and the child's task was to reproduce the dot pattern from memory on a blank matrix drawn on a transparency that overlaid a magnetic drawing board. A round magnet was used to reproduce dot patterns.

Phonological Coding. Two experimental measures of working memory were used as proxy measures of Phonological Coding: phonological memory and memory for abstract words. Both these measures involved storage and retrieval of spoken syllables devoid of concrete referential meaning. Thus, given theory and research documenting the importance of speech-coding processes for holding information in working memory (Baddeley, 1986), both were assumed to rely heavily on Phonological Coding ability. Moreover, both types of measures have been found to correlate reliably with measures of phonological skills (e.g., letter-sound decoding, phonological awareness, etc.), especially in beginning readers, and both have been found to correlate more highly with these latter measures than with nonverbal measures (Vellutino et al., 1991; Vellutino et al., 1994; see also Table 1). Finally, tests evaluating phonological memory and memory for abstract words have also been found to reliably discriminate between poor and normal readers (e.g., Vellutino \& Scanlon, 1987b; Vellutino et al., 1996). This is notable because poor readers tend to have weak phonological skills.

On the phonological memory test, children were given eight trials to learn a list of six phonologically redundant nonsense syllables presented orally using the presentation/test (free recall) format on each trial. There were two lists of nonsense syllables (des, seeg, seg, geez, deez, dez; zeb, vab, zep, zab, pev, pav), and each list was randomly assigned to a given participant. Stimuli within a list were presented randomly on each trial. The presentation and test components of a given trial were separated by a 6-sec hiatus, during which the child counted backward from a randomly selected number (by twos for second and third graders and by threes for sixth and seventh graders). The syllables on a list were presented at a rate of one per second, and on each trial the child was given $15 \mathrm{sec}$ to recall as many as he or she could remember.

The memory for abstract words measure was taken from a word memory test that included both concrete and abstract words. On this test the children were given six trials to learn a list of 12 common words: 6 concrete words (cake, house, jar, 
play, push, star) and 6 abstract words (give, hope, joy, month, truth, want), equated for meaning and frequency of occurrence in children's basal readers (Harris \& Jacobson, 1982). All 12 words were presented orally on each trial, and the concrete and abstract words were randomly interspersed. The presentation/test (free recall) format was used on each trial, and there was a 2 -sec interval between words. Between list presentation and testing, the child counted backward for $20 \mathrm{sec}$ (by ones for second and third graders and by twos for sixth and seventh graders) and was thereafter given $15 \mathrm{sec}$ for recall. Separate tallies were made for each word set, but because recall of concrete words was assumed to depend more on semantic coding than on phonological coding, a child's performance on the concrete word stimuli was not used as a measure of Phonological Coding. Thus a child's raw score was the total number of abstract words recalled across trials.

\section{Endogenous Latent Constructs}

Visual Analysis. The Block Design subtest from the Performance Scale of the WISC-R was used as the measure of Visual Analysis because it requires analysis and synthesis of visual part-whole relationships and attention to visual detail. It entails assembly of colored blocks to form geometric designs, either modeled by the examiner or presented pictorially.

Phonological Awareness. Phonological Awareness was evaluated using two experimental tests of phoneme awareness: phoneme localization and phoneme articulation. Both types of measures have been found, in numerous studies, to be reliably correlated with other measures of phonological skills and related word-level skills and to reliably distinguish between poor and normal readers (e.g., Vellutino et al., 2004; Vellutino et al., 1996; Vellutino et al., 1991; Vellutino et al., 1994; see also Table 1). On both tests, children were orally presented with 10 pairs of minimally contrasted words comprising either two or three phonemes (e.g., pin/pen). The phoneme localization test required that the child judge whether the sounds that were different in each pair were located at the beginning, middle, or end of the words. The phoneme articulation test required the child to vocalize the sounds that were different in each word pair. The test stimuli were administered after presentation of two practice items that involved modeling, feedback, and any necessary clarification as to task demands. Both tests were administered in the same session, and the phoneme localization test was always administered first. The child's score on each test was the total number of correct responses, as judged by a trained examiner.

Semantic Knowledge. Two subtests from the WISC-R Verbal Scale were used as alternative measures of Semantic Knowledge: Vocabulary and Similarities. The Vocabulary subtest evaluates the child's ability to provide oral definitions of 
words that increase in difficulty and degree of abstractness. The Similarities subtest evaluates the child's ability to detect and describe commonalities between two words representing objects or concepts. Word pairs also increase in difficulty and degree of abstractness.

Syntactic Knowledge. Syntactic Knowledge was evaluated using an experimental test that asked the child to judge whether orally presented sentences were grammatically well formed: grammaticality judgments. This test has been found to correlate significantly with measures of language and reading comprehension as well as with other language-based measures (Vellutino et al., 1996; Vellutino et al., 1991; Vellutino et al., 1994; see also Table 1). The child's task was to indicate whether a sentence heard was correct or had "a mistake in it." There was a total of 20 sentences, 16 that were grammatically ill formed and 4 that were grammatically well formed (e.g., The old man which lives near Cheryl's mother has ten children vs. A man who knows my father is coming to our party). Two practice sentences were administered before administration of the test proper, and corrective feedback was provided.

Phonological Decoding. The Word Attack subtest from the Woodcock-Johnson Psychoeducational Battery (Woodcock \& Johnson, 1977) was used as the measure of Phonological Decoding. This test involves oral pronunciation of pseudowords.

Spelling. One subtest from the Test of Written Spelling-2 (Larsen \& Hammill, 1986) was used as the measure of Spelling. This test assessed the child's written spelling of phonetically regular words dictated by the examiner.

Context-Free Word Identification. The Letter-Word Identification subtest from the Woodcock-Johnson Psycho-Educational Battery (Woodcock \& Johnson, 1977) was used to assess Context-Free Word Identification. This test is graded in difficulty and entails oral naming of printed words presented in isolation.

Language Comprehension. The Listening Comprehension subtest of the Spache Diagnostic Reading Scales (SDRS; Spache, 1981) was used to evaluate the child's ability to comprehend narrative text presented orally. It consists of several graded passages (preprimer through Grade 7), each of which is followed by questions about the content of the passage. However, to avoid ceiling effects, especially in the Older group, two additional passages from the Interactive Reading Assessment System (IRAS; Calfee \& Calfee, 1981) were added to the SDRS passages at each grade level. 
Reading Comprehension. The Reading Comprehension subtest from the SDRS (Spache, 1981) was used to evaluate the ability to comprehend narrative text read silently. This test consists of several graded passages (Grades 1-7), followed by questions about each passage. To avoid ceiling effects, two passages from the IRAS were added to the test, and one credit was given for each question answered correctly. Note also that the SDRS Reading and Listening Comprehension subtests were constructed so as to have comparable levels of difficulty at each grade level in terms of such variables as genre (e.g., narrative vs. expository), vocabulary, number of words per sentence, sentence length, number of propositions per sentence, number of paragraphs, and so forth. The same is true of the IRAS Reading and Listening Comprehension subtests.

\section{Itinerary}

Data for this study were collected over a 3-year period. Fifty public and private elementary and middle schools were involved in the study. Sample selection was conducted during the fall of each school year, and the tests evaluating the various latent constructs of interest were administered between late January and early June of the same school year. Administration of the entire battery encompassed five sessions, each of which was approximately $45 \mathrm{~min}$ in length. Testing sessions were separated by a minimum of 1 day and a maximum of 2 weeks and were arranged to accommodate daily schedules in participating schools. All testing was done on a one-to-one basis in a quiet setting in the child's school.

\section{Data Analysis}

Confirmatory factor analyses using LISREL software (Jöreskog \& Sörbom, 1993a) were conducted to initially evaluate the Convergent Skills Model. We first assessed the validity of the model by fitting it to observed covariance matrices obtained from the two different age/grade groups. After ensuring adequate fit in each group separately, we performed a series of multigroup solutions in which the model was evaluated for both groups simultaneously using the nested chi-square strategies discussed by Jaccard and Wan (1996). ${ }^{2}$ Bootstrap analyses were thereaf-

\footnotetext{
${ }^{2}$ Significance tests for differences between the unstandardized coefficients of the two age/grade groups were conducted using the LISREL 8 Multigroup Comparison procedure (Jaccard \& Wan, 1996). This procedure requires the establishment of a "base model," which entails stacking the two groups without equality constraints, and thereafter running the LISREL program for the two age/grade groups combined, leaving all coefficients free to vary. This analysis resulted in $\chi^{2}(120)=141.42, p=$ .10. Each a priori comparison of interest was then undertaken by constraining the two path coefficients for a given causal relationship to be equal across the two groups. The chi-square produced by the constrained model was then compared with that for the unconstrained or base model, and a chi-square difference equal to or greater than 3.84 was taken as statistically significant $(p \leq .05)$. To illustrate, con-
} 
ter conducted to evaluate stability of parameter estimates using AMOS software (Arbuckle, 1997).

Before presenting results from these analyses, we should point out that the directional arrows connecting latent constructs in our model (Figure 1) signify causal relationships only in the theoretical sense because assessment of these relationships is based on correlational rather than experimental data. Thus the path coefficients for relationships between given constructs are best interpreted as indexes of the degree to which measured change in one construct covaries with measured change in another construct when the effects of all other constructs are held constant (see Footnote 3). Because the model was assessed using cross-sectional rather than longitudinal data, it was not possible to evaluate either the time course of developmental change in the hypothesized relationships between given constructs or the degree to which these constructs may be reciprocally related. Therefore results should be interpreted with these limitations in mind.

Finally, given that the children who served as participants in this study were selected and grouped on the basis of reading ability and not on the basis of a random selection procedure, those children in the extreme ranges of the distributions generated by the observed measures used to define latent constructs will tend to be overrepresented in these ranges. This circumstance could spuriously inflate correlations and, thereby, parameter estimates. Thus caution is indicated in interpreting these results.

\section{RESULTS AND DISCUSSION}

Table 1 presents the correlation matrices along with relevant descriptive statistics for the observed measures operationally defining the various latent constructs for both the Younger and Older groups. Correlations for the Younger group are in the upper triangle, and correlations for the Older group are in the lower triangle. Although the fit statistics and path coefficients discussed later were derived from the covariance matrices for these two groups, we present correlation matrices to show relationships between observed measures for ease of interpretation. For purposes of comparison, Table 2 presents the factor loadings depicting the relationship between latent constructs and observed measures for both reader groups. Coeffi-

straining the path coefficients for the relationship between Context-Free Word Identification and Reading Comprehension to be equal in the two age/grade groups produced a chi-square of 205.15 , which, relative to the chi-square for the unconstrained base model, accords with a statistically significant difference of 64.60 , or $\chi^{2}(1)=64.60, p<.01$. This indicates that the relationship between Context-Free Word Identification and Reading Comprehension is significantly stronger in the younger group than it is in the older group. 
TABLE 1

Correlation Matrix for Observed Measures: Younger and Older Reader Groups

\begin{tabular}{|c|c|c|c|c|c|c|c|c|c|c|c|c|c|c|}
\hline \multirow[b]{2}{*}{ Older } & \multicolumn{14}{|c|}{ Younger } \\
\hline & $\begin{array}{l}\text { Read } \\
\text { Comp }\end{array}$ & $\begin{array}{l}\text { Word } \\
\text { Ident }\end{array}$ & $\begin{array}{l}\text { Lang } \\
\text { Comp }\end{array}$ & $\begin{array}{l}\text { Gram } \\
\text { Judge }\end{array}$ & Simil & Vocab & $\begin{array}{c}\text { Phon } \\
\text { Decod }\end{array}$ & $\begin{array}{l}\text { Blck } \\
\text { Desg }\end{array}$ & $\begin{array}{c}\text { Phon } \\
\text { Art }\end{array}$ & $\begin{array}{c}\text { Phon } \\
\text { Loc }\end{array}$ & Spell & $\begin{array}{l}\text { Phon } \\
\text { Mem }\end{array}$ & $\begin{array}{l}\text { Mem } \\
\text { Abst }\end{array}$ & $\begin{array}{c}\text { Mem } \\
\text { Sp Loc }\end{array}$ \\
\hline Read Comp & & 0.80 & 0.67 & 0.33 & 0.45 & 0.51 & 0.65 & 0.26 & 0.43 & 0.37 & 0.73 & 0.42 & 0.43 & 0.28 \\
\hline Word Ident & 0.43 & & 0.53 & 0.27 & 0.45 & 0.48 & 0.75 & 0.24 & 0.45 & 0.37 & 0.78 & 0.47 & 0.44 & 0.24 \\
\hline Lang Comp & 0.79 & 0.42 & & 0.27 & 0.53 & 0.64 & 0.41 & 0.36 & 0.32 & 0.29 & 0.51 & 0.34 & 0.31 & 0.21 \\
\hline Gram Judge & 0.34 & 0.47 & 0.38 & & 0.17 & 0.21 & 0.24 & 0.17 & 0.19 & 0.14 & 0.29 & 0.12 & 0.10 & 0.16 \\
\hline Simil & 0.38 & 0.54 & 0.46 & 0.36 & & 0.59 & 0.35 & 0.39 & 0.28 & 0.25 & 0.47 & 0.27 & 0.22 & 0.23 \\
\hline Vocab & 0.59 & 0.64 & 0.68 & 0.49 & 0.56 & & 0.34 & 0.42 & 0.29 & 0.27 & 0.47 & 0.35 & 0.25 & 0.26 \\
\hline Phon Decod & 0.22 & 0.73 & 0.22 & 0.34 & 0.36 & 0.37 & & 0.24 & 0.54 & 0.36 & 0.78 & 0.45 & 0.39 & 0.24 \\
\hline Blck Desg & 0.24 & 0.39 & 0.30 & 0.18 & 0.32 & 0.38 & 0.24 & & 0.16 & 0.19 & 0.30 & 0.12 & -0.02 & 0.38 \\
\hline Phon Art & 0.19 & 0.46 & 0.26 & 0.31 & 0.31 & 0.35 & 0.59 & 0.17 & & 0.48 & 0.46 & 0.28 & 0.21 & 0.13 \\
\hline Phon Loc & 0.28 & 0.30 & 0.34 & 0.18 & 0.25 & 0.35 & 0.25 & 0.15 & 0.44 & & 0.36 & 0.26 & 0.21 & 0.15 \\
\hline Spell & 0.41 & 0.78 & 0.43 & 0.44 & 0.49 & 0.58 & 0.70 & 0.24 & 0.49 & 0.32 & & 0.44 & 0.43 & 0.25 \\
\hline Phon Mem & 0.18 & 0.38 & 0.21 & 0.19 & 0.21 & 0.20 & 0.44 & 0.12 & 0.35 & 0.19 & 0.46 & & 0.47 & 0.08 \\
\hline Mem Sp Loc & 0.08 & 0.12 & 0.19 & 0.09 & 0.17 & 0.12 & 0.09 & 0.40 & 0.10 & 0.08 & 0.11 & 0.06 & 0.13 & \\
\hline $\mathrm{R} *(\mathrm{Y})$ & 0.91 & 0.96 & 0.91 & 0.66 & 0.85 & 0.74 & 0.95 & 0.85 & 0.84 & 0.62 & 0.86 & 0.75 & 0.51 & 0.80 \\
\hline$M(\mathrm{Y})$ & 47.80 & 28.77 & 51.65 & 11.74 & 11.88 & 24.99 & 9.40 & 19.23 & 4.40 & 5.81 & 11.41 & 17.69 & 14.13 & 12.22 \\
\hline$S D(\mathrm{Y})$ & 13.49 & 5.28 & 11.31 & 2.87 & 3.65 & 5.80 & 5.10 & 9.27 & 2.63 & 2.32 & 6.88 & 6.87 & 5.87 & 3.56 \\
\hline $\mathrm{R} *(\mathrm{O})$ & 0.98 & 0.88 & 0.98 & 0.51 & 0.84 & 0.91 & 0.88 & 0.89 & 0.84 & 0.77 & 0.97 & 0.89 & 0.44 & 0.73 \\
\hline$M(\mathrm{O})$ & 70.00 & 39.67 & 69.82 & 13.31 & 17.37 & 37.99 & 16.09 & 35.52 & 5.91 & 7.21 & 28.38 & 25.25 & 20.23 & 16.81 \\
\hline$S D(\mathrm{O})$ & 10.16 & 4.33 & 12.78 & 2.83 & 3.71 & 6.85 & 5.20 & 11.32 & 2.58 & 2.01 & 7.36 & 8.19 & 5.98 & 2.27 \\
\hline Maximum & & & & & & & & & & & & & & \\
\hline raw scores & 100 & 54 & 100 & 20 & 30 & 64 & 26 & 62 & 10 & 10 & 50 & 48 & 36 & 22 \\
\hline
\end{tabular}

Note. $\quad$ Read Comp $=$ Spache Reading Comprehension; Word Ident $=$ Woodcock-Johnson Word Identification; Lang Comp $=$ Spache Listening Comprehension; Gram Judge = Grammaticality Judgments; Simil = WISC - R Similarities; Vocab = WISC - R Vocabulary; Phon Decod = Woodcock-Johnson Word At tack; Blck Desg = WISC - R Block Design; Phon Art $=$ Phonological Articulation; Phon Loc $=$ Phonological Location; Spell $=$ Test of Written Spelling; Phon Mem = Phonological Memory; Mem Abst = Memory for Abstract Words; Mem Sp Loc = Memory for Spatial Location; $* \mathrm{R}=$ Reliability; $(\mathrm{Y})=$ younger group; $(\mathrm{O})$ = older group. 
TABLE 2

Factor Loadings for the Relationship Between Observed Measures and Latent Constructs

\begin{tabular}{|c|c|c|c|}
\hline \multirow[b]{2}{*}{ Latent Constructs } & \multirow[b]{2}{*}{ Observed Measures } & \multicolumn{2}{|c|}{ Factor Loadings } \\
\hline & & Younger & Older \\
\hline \multirow[t]{2}{*}{ Phonological Coding } & Phonological Memory ${ }^{\mathrm{a}}$ & $1.00(.68)$ & $1.00(.75)$ \\
\hline & Memory for Abstract Words ${ }^{\mathrm{a}}$ & $.85(.67)$ & $.34(.35)$ \\
\hline Visual Coding & Memory for Spatial Location ${ }^{\mathrm{a}}$ & $1.00(.89)$ & $1.00(.85)$ \\
\hline Visual Analysis & WISC-R Block Design & $1.00(.91)$ & $1.00(.94)$ \\
\hline \multirow[t]{2}{*}{ Phonological Awareness } & Phonological Articulation ${ }^{\mathrm{a}}$ & $1.00(.82)$ & $1.00(.92)$ \\
\hline & Phonological Location ${ }^{\mathrm{a}}$ & $.65(.60)$ & $.39(.45)$ \\
\hline \multirow[t]{2}{*}{ Semantic Knowledge } & WISC-R Similarities & $1.00(.72)$ & $1.00(.64)$ \\
\hline & WISC-R Vocabulary & $1.81(.81)$ & $2.61(.90)$ \\
\hline Syntactic Knowledge & Grammatical judgments $\mathrm{a}^{\mathrm{a}}$ & $1.00(.81)$ & $1.00(.71)$ \\
\hline Phonological Decoding & Woodcock-JohnsonWord Attack & $1.00(.96)$ & $1.00(.94)$ \\
\hline Spelling & Test of Written Spelling & $1.00(.93)$ & $1.00(.98)$ \\
\hline $\begin{array}{l}\text { Context-Free Word } \\
\text { Identification }\end{array}$ & $\begin{array}{l}\text { Woodcock-Johnson Letter-Word } \\
\text { Identification }\end{array}$ & $1.00(.98)$ & $1.00(.94)$ \\
\hline Language Comprehension & Spache Listening Comprehension & $1.00(.95)$ & $1.00(.95)$ \\
\hline Reading Comprehension & Spache Reading Comprehension & $1.00(.97)$ & $1.00(.95)$ \\
\hline
\end{tabular}

Note. When one observed measure defined a latent construct, the factor loading for that measure was fixed at 1.00. When two observed measures defined a latent construct, the factor loading for one of these measures (the reference indicator) was fixed at 1.00 to metricize the construct, and the factor loading for the other measure was estimated. Standardized factor loadings are in parentheses. WISC-R = Wechsler Intelligence Scale for Children-Revised.

axperimental measures.

cients assigned the value 1.00 were fixed parameters, and all others were estimated. Standardized coefficients are in parentheses.

The data generating the covariance matrices for the Younger and Older groups were evaluated for multivariate outliers in each group using Cook's distance and leverage indexes for each individual. The presence of multivariate outliers would be suggested by a significant chi-square for Cook's distance and/or a leverage score five times greater than the mean leverage. No outliers were detected. Multivariate normality was evaluated using PRELIS Version 2 (Jöreskog \& Sörbom, 1993a). For the Younger group the univariate skewness measures ranged from -0.72 to 1.21 with a median of 0.07 . The kurtosis measures ranged from -1.08 to 2.24 with a median of -0.20 . For the Older group the corresponding ranges were -1.71 to $0.38(M d n=0.14)$ for skewness and -1.17 to $2.97(M d n=$ -0.53 ) for kurtosis. These values are within the limits of robust estimation observed in a number of robustness studies on maximum likelihood using LISREL (Jaccard \& Wan, 1996). The multivariate indexes of nonnormality provided in PRELIS were not used because of the small sample size in this study, relative to the 
sample size demands of these statistics (Jaccard \& Wan, 1996). To ensure that our results were robust to any nonnormality in the system, we estimated the chi-square test of model fit and the standard errors for the path coefficients using both traditional maximum likelihood analysis and bootstrap-based methods (Arbuckle, 1997). Finally, the nested chi-square tests for the multigroup solutions were conducted under the constraint that the $\lambda X$ and $\lambda Y$ matrices be equivalent across groups (Jaccard \& Wan, 1996). Adding this constraint did not significantly affect model fit. However, the values of the path coefficients reported and their tests of significance are based on the unconstrained solutions. We focus first on the traditional maximum likelihood analysis and then report results from the bootstrap analysis.

\section{Overall Model Fit}

Six indexes were used to evaluate model fit: the traditional chi-square test based on maximum likelihood analysis, the root mean square error of approximation (RMSEA), the standardized root mean square residual (RMR), the comparative fit index (CFI), the goodness of fit index (GFI), and the normed fit index (NFI). Statistically nonsignificant chi-squares suggest acceptable model fit, as do statistically nonsignificant RMSEAs that are no greater than 0.08; standardized RMRs that are no greater than 0.05; and CFIs, GFIs, and NFIs of 0.90 or better (Jaccard \& Wan, 1996). The chi-squares were as follows: $\chi^{2}(60, N=297)=74.39, p=.10$ for the Younger group and $\chi^{2}(60, N=171)=67.03, p=.25$ for the Older group. The RMSEA was $0.03, p=.97$ and $0.03, p=.90$ for the Younger and Older group, respectively. The standardized RMR was 0.04 and 0.05 for the Younger and Older group, respectively. The CFI was 0.99 for both groups, and the GFI was 0.97 for the Younger group and 0.95 for the Older group. Finally, the NFI was 0.96 for the Younger group and 0.94 for the Older group. All indexes point to adequate model fit.

The combined chi-square for the models in the multigroup solution was $\chi^{2}(120)$ $=141.42, p=.10$. Similarly, the RMSEA was $0.02, p=1.00$; the standardized RMR was 0.05 ; the CFI was 0.99 ; the GFI was 0.95 ; and the NFI was 0.95 . When the constraint for equivalent measurement models was added (i.e., equivalent $\lambda X$ and $\lambda Y$ matrices across groups), the change in model chi-square was statistically significant, $\chi^{2}(3)=20.61, p<.01$, but the other global fit indexes continued to reflect good model fit. Examination of the path coefficients from the latent variables to the observed indicators in both the constrained and unconstrained solutions revealed no single path where group differences were notable in terms of the issue of measurement invariance. Given the generally favorable global fit indexes in the constrained solution and the comparability in the magnitudes of the coefficients in the measurement model for the two groups in both the constrained and unconstrained solutions, the analysis was pursued under the assumption of measurement invariance across groups. As an additional check, significance tests were repeated, 
changing the reference indicator for each latent variable (where multiple indicators were present) to ensure that the results of these tests replicated across different reference indicators. This was true in all cases.

The overall pattern of results, then, suggests that the specified model is acceptable for both age/grade groups and thus speaks for the viability of the Convergent Skills Model of Reading Development in terms of both the basic assumptions of the model and the hypothesized relationships among the latent constructs specified by the model. Additional support is provided by the path coefficients confirming these relationships. However, before discussing these results, we should point out that the model specified earlier did not hypothesize a causal relationship between Visual Analysis and Phonological Awareness (see Figure 1), but inspection of the modification indexes produced by preliminary analyses evaluating the model suggested that a causal path between these constructs be established in the interest of a better model fit. The final model therefore incorporates this modification, and the fit indexes reported earlier are based on this model.

\section{Path Coefficients for Hypothesized Causal Relationships}

Figure 1 presents the path coefficients depicting hypothesized causal relationships among the various latent constructs. Coefficients for the Younger group always appear above coefficients for the Older group. We present unstandardized coefficients because they are the appropriate metric for testing differences between the two populations using the nested chi-square test (Jaccard \& Wan, 1996). However, for purposes of comparison, standardized coefficients are enclosed in parentheses. ${ }^{3}$ As indicated earlier, our evaluation of the Convergent Skills Model putatively addresses two intrinsically related questions for understanding how a child learns to read: developmental differences in the respective contributions made by Context-Free Word Identification and Language Comprehension to Reading Comprehension and both individual and developmental differences in the contributions made by skills and abilities underlying Context-Free Word Identification and Language Comprehension to Reading Comprehension. Regarding the first question, it can be seen that the path coefficient for the relationship between Context-Free

\footnotetext{
${ }^{3}$ For the reader who is unacquainted with structural equation modeling we offer the following simplified description of path analysis. First, note that a path coefficient can be thought of as a statistical index depicting the strength of a hypothesized causal relationship between two constructs when the effects of all other constructs are held constant. In the case of unstandardized coefficients a significant coefficient indicates that for every unit increase in the predictor variable (in raw score units), there will be an increase (or decrease, if the sign is negative) in the predicted variable in the amount signified by that coefficient. Thus in the present instance the coefficient for the path connecting Context-Free Word Identification with Reading Comprehension was found to be 1.65 in the Younger group, which indicates that Reading Comprehension is predicted to increase 1.65 raw score units ( 0.64 standard score units) for every unit increase in Context-Free Word Identification.
} 
Word Identification and Reading Comprehension is statistically significant in the Younger group but not in the Older group, as predicted. Moreover, the multigroup analysis comparing constrained and unconstrained versions of this path produced statistically significant differences in model fit, $\chi^{2}(1)=65.96, p<.01$. The coefficient for the path between Language Comprehension and Reading Comprehension achieved statistical significance in both reader groups, but the multigroup analysis indicated that the coefficient for the Older group was significantly larger than the coefficient for the Younger group, $\chi^{2}(1)=10.90, p<.01$, as also predicted.

These results essentially replicate previous research findings (Curtis, 1980; Hoover \& Gough, 1990; Sticht, 1979) and are in keeping with the assumption that language comprehension processes do not become fully operative in reading until the child is able to identify the printed versions of the vast majority of words he or she is able to comprehend in spoken language. More specifically, the results suggest that most children in the Older group had acquired enough facility in word identification to allow language comprehension processes to play the dominant role in accounting for variability in reading comprehension, whereas this was not true of most children in the Younger group. Although language comprehension processes may not have been fully operative as determinants of reading comprehension in all the children in either group, they were, quite likely, closer to this level of functioning in children in the Older group than in children in the Younger group.

Regarding the question of whether there are individual and developmental differences in the relative contributions made by skills and abilities underlying the major components of reading ability, results are generally consistent with our predictions. First, note that the path coefficients for hypothesized relationships between Phonological Coding and phonologically based word-level skills (Phonological Awareness, Phonological Decoding, Spelling, and Context-Free Word Identification), in most instances, were found to be statistically significant. The only exceptions occurred in the cases of the path coefficients for the relationship between Phonological Coding and Phonological Decoding and for the relationship between Phonological Coding and Context-Free Word Identification. Neither of these coefficients was statistically significant in either reader group. Because Phonological Coding is assumed to facilitate representation of syllables and phonemes and thereby the learning of letter names, letter sounds, and the names of printed words as wholes, we postulated direct causal relationships between Phonological Coding and both Phonological Decoding and Context-Free Word Identification (respectively), but the results suggest that these relationships are mediated by Phonological Awareness and Spelling. A tentative interpretation of these findings is that in children from the age/grade populations studied herein the acquisition of facility in both phonological decoding and word identification depends more on phoneme analysis, letter-sound analysis, and spelling than on the type of wholistic encoding implied in processing letter strings as unanalyzed units (see Ehri, 1991, and Tunmer \& Chapman, 1998, for similar views). 
However, among the phonological skills hypothesized to be directly or indirectly linked to Context-Free Word Identification (Phonological Awareness, Phonological Decoding, and Spelling), the only coefficient that did not achieve statistical significance was that corresponding to the link between Phonological Awareness and Spelling in the Older group. Moreover, observed differences in the path coefficients generated by the two groups did not achieve statistical significance in any of the multigroup solutions. Thus it would appear that some phonological skills that support the acquisition of facility in word identification among elementary school readers continue to be influential in acquiring this skill in middle school readers. Yet, as is evident in Table 3, the total effects of these phonological skills on Reading Comprehension tended to be greater in the Younger group than in the Older group. ${ }^{4}$ Of the path coefficients for the total effects of word-level phonological skills on Reading Comprehension, all achieved statistical significance in the Younger group, but only one did so in the Older group, specifically, the path coefficient for the total effect of Spelling on Reading Comprehension. However, this coefficient was found to be statistically significant because of the direct and indirect contributions that Spelling made to Semantic Knowledge and Language Comprehension. Thus in accord with expectations, phonological and word-level skills were more influential determinants of reading comprehension in children close to the beginning stages of reading development than in children at more advanced stages.

Regarding the effects of Semantic and Syntactic Knowledge on reading ability, we should first point out that the path coefficient associated with the hypothesized relationship between Semantic Knowledge and Language Comprehension was statistically significant in both the Younger and the Older groups whereas the magnitude of the coefficient was greater in the Older group. However, this difference did not achieve statistical significance in the multigroup analysis, contrary to expectations. At the same time, Semantic Knowledge was found to be related to Context-Free Word Identification in both the Younger and Older groups, and the coefficient was larger in the Older group, though not significantly so. Moreover, the total effect of Semantic Knowledge on Reading Comprehension was statistically significant in both the Younger and Older groups (see Table 3). These findings suggest that Semantic Knowledge is a strong and influential determinant of Language and Reading Comprehension in both early and late-stage readers and appears to

\footnotetext{
${ }^{4}$ Total effects in structural equation modeling constitute the combined effects of one latent construct on another latent construct, and the path (beta) coefficient representing such effects in any given case is a composite measure of both the direct and indirect effects of the former on the latter. Thus the total effect of Phonological Coding on Context-Free Word Identification consists of whatever direct effect Phonological Coding has on Context-Free Word Identification in addition to indirect or mediated effects generated by the links between and among Phonological Coding, Phonological Awareness, Phonological Decoding, Spelling, and Semantic Knowledge, all of which are directly and/or indirectly linked to Context-Free Word Identification.
} 
TABLE 3

Regression Coefficients for the Total Effects of Phonological, Semantic, Syntactic, and Visual Skills on Reading Comprehension in the Younger and Older Reader Groups

\begin{tabular}{lccccc}
\hline & \multicolumn{2}{c}{ Younger } & & \multicolumn{2}{c}{ Older } \\
\cline { 2 - 3 } \cline { 5 - 6 } & \multicolumn{1}{c}{$B$} & & & & \\
& & & & & \\
\hline Phonological skills & & & & & \\
$\quad$ Phonological Coding & $1.72(.61)$ & $7.82^{*}$ & & $.28(.18)$ & 1.77 \\
Phonological Awareness & $1.22(.20)$ & $3.60^{*}$ & & $.46(.12)$ & 1.90 \\
Phonological Decoding & $.36(.13)$ & $2.39^{*}$ & & $.04(.02)$ & .73 \\
$\quad$ Spelling & $1.09(.54)$ & $7.92^{*}$ & & $.59(.44)$ & $5.32^{*}$ \\
Semantic/syntactic skills & & & & \\
$\quad$ Semantic Knowledge & $1.85(.37)$ & $6.11^{*}$ & & $2.67(.66)$ & $7.03^{*}$ \\
$\quad$ Syntactic Knowledge & $.17(.03)$ & 1.37 & & $-.54(-.12)$ & -.70 \\
Visual skills & & & & $.66(.14)$ & $3.54^{*}$ \\
$\quad$ Visual Coding & $.52(.13)$ & $4.57^{*}$ & & $.27(.29)$ & $4.84^{*}$ \\
$\quad$ Visual Analysis & $.42(.27)$ & $5.84^{*}$ & & & \\
\hline
\end{tabular}

Note. Standardized coefficients are in parentheses. $* p<.01$.

have a substantial influence on Context-Free Word Identification as well as on Language Comprehension.

Somewhat surprisingly, the coefficient for the relationship between Syntactic Knowledge and Language Comprehension was not found to be statistically significant in either reader group. The reason for this finding is not entirely clear, but it is possible that Syntactic Knowledge did not explain unique variance in Language Comprehension beyond that explained by Semantic Knowledge because of considerable shared variance among the measures used to define these constructs. The finding of a significant path coefficient for the causal link between Semantic and Syntactic Knowledge in both developmental groups lends some support to this possibility (see Figure 1). It is also possible that the syntactic awareness task we used to measure Syntactic Knowledge may not have been optimal for present purposes and that a more direct measure of this construct may have been more strongly and more uniquely related to Language Comprehension, for example, a measure evaluating sentence comprehension rather than syntactic awareness.

Additional findings of note are as follows. The path coefficients for the hypothesized links between Phonological Coding and both Semantic Knowledge and Language Comprehension (respectively) were found to be statistically significant in the Younger group but not in the Older group, whereas the path coefficient for the hypothesized link between Phonological Coding and Syntactic Knowledge was not found to be statistically significant in either group. In contrast, the path coefficient 
for the link between Spelling and Semantic Knowledge was found to be statistically significant in both groups, but the group mean difference was not significant.

Results generated by the visual components of the model were generally in accord with expectations. Visual Coding was found to be significantly related to Visual Analysis, as anticipated, but the relationship was found to be significantly stronger in the Older group than in the Younger group, $\chi^{2}(1)=5.66, p<.01$. At the same time, Visual Analysis was significantly related to Phonological Awareness, Spelling, and Semantic Knowledge in both the Younger and Older groups, but it was related to Context-Free Word Identification only in the Older group. Thus the relationship between these visual skills and Context-Free Word Identification was largely mediated by Phonological Awareness, Spelling, Phonological Decoding, and Semantic Knowledge, and although the total effects of Visual Coding and Visual Analysis on Reading Comprehension were substantial in both the Younger and Older groups (see Table 3), all these effects were mediated by language-based abilities, as we predicted.

Finally, Table 4 presents squared multiple correlations for variance explained by the Convergent Skills Model in each latent construct for both the Younger and Older reader groups. Each of these indexes represents the total amount of variance in a criterion latent construct (e.g., Reading Comprehension) that is explained by the model as a whole, as an additive function of the variance contributed by all the predictors having direct and/or indirect links to that construct. It can be seen that the model accounted for over $50 \%$ of the variance in most of the latent constructs in both groups. Especially impressive is the finding that the model accounted for approximately $80 \%$ of the variance in Reading Comprehension in the Younger group and $77 \%$ of the variance in this construct in the Older group. Similarly, the model accounted for $79 \%$

TABLE 4

Squared Multiple Correlations Depicting Amount of Explained Variance Among Endogenous Latent Constructs Specified by the Convergent Skills Model

\begin{tabular}{lcc}
\hline & \multicolumn{2}{c}{ Reader Groups } \\
\cline { 2 - 3 } Latent Constructs & Younger & Older \\
\hline Reading Comprehension & .80 & .77 \\
Context-Free Word Identification & .79 & .88 \\
Language Comprehension & .67 & .57 \\
Semantic Knowledge & .58 & .51 \\
Syntactic Knowledge & .13 & .60 \\
Phonological Decoding & .77 & .66 \\
Spelling & .62 & .46 \\
Phonological Awareness & .29 & .25 \\
Visual Analysis & .25 & .21 \\
\hline
\end{tabular}


of the variance in Context-Free Word Identification in the Younger group and $88 \%$ of the variance in the Older group. Note, however, that the total amount of variance contributed by given constructs to a criterion construct may change across reader groups, despite the fact that the total amount of explained variance in a construct may be comparable in the two groups. Thus, although the percentage of explained variance in Reading Comprehension is comparable in the Younger and Older groups, Context-Free Word Identification contributes less to that percentage in the Older group than it does in the Younger group.

\section{Bootstrapping Results}

To evaluate the robustness of these results across alternative forms of model estimation, we used the AMOS bootstrapping program (Arbuckle, 1997), which allowed us to estimate the population coefficients and standard errors for the two reader groups, while compensating, to some extent, for nonnormality in the data. This analysis used 2,000 bootstrapped samples to generate $95 \%$ confidence intervals and significance tests for each of the model parameters (Effron \& Tibishirani, 1993). The analysis revealed that the following coefficients were no longer statistically significant following the boostrapping procedure: in the Younger group, those representing causal links between Phonological Coding and Semantic Knowledge, Spelling and Semantic Knowledge, and Semantic Knowledge and Context-Free Word Identification; in the Older group, those representing causal links between Visual Analysis and Phonological Awareness, Visual Analysis and Spelling, Visual Analysis and Context-Free Word Identification, Phonological Decoding and Context-Free Word Identification, Spelling and Semantic Knowledge, Spelling and Phonological Decoding, and Spelling and Context-Free Word Identification. On the basis of these results we conducted several additional analyses wherein we systematically evaluated model fit after eliminating each of the causal paths that did not survive the bootstrapping procedure, and we found, with one exception, that model fit remained acceptable after eliminating a given path and that little else changed. The one exception to this pattern occurred when we eliminated the causal path between Spelling and Semantic Knowledge, which had different effects on the Younger and Older groups. Eliminating this path had no strong degrading effect on model fit in the Younger group but produced an unacceptable model in the Older group, suggesting that a causal path between Spelling and Semantic Knowledge is a necessary component of the model in this group.

\section{Additional Analyses}

As an additional means of ensuring our results were robust, we also conducted directed regression analyses on the model using traditional least squares regression methods. Specifically, we regressed each endogenous variable in the model onto 
its predictor variables and examined the statistical significance of the regression coefficients. In cases where a construct was represented by more than a single indicator we arbitrarily choose one of the indicators to represent the construct in the regression equation. This procedure has the advantage of using the generally robust ordinary least squares (OLS) approach, and, unlike the full information estimation approach used by structural modeling programs such as LISREL, it yields localized path estimates that are unaffected by points of stress caused by misspecification of causal relationships in other portions of the model. The traditional OLS approach has the disadvantage of yielding less efficient estimators, owing to greater sampling error than the full information estimation approach, and it fails to provide indexes of overall fit. To test for differences in younger versus older readers in the OLS approach, product terms were introduced using the procedures described by Jaccard, Turrisi, and Wan (1990). The results were generally consistent with those produced by the LISREL analysis in terms of the magnitudes of both the path coefficients evaluating causal relationships specified in the model and the central hypotheses evaluated in this study.

\section{GENERAL DISCUSSION}

This study assessed hypothesized causal relationships among the major skills and cognitive abilities underlying reading ability, along with developmental changes in these relationships, within the context of a theoretical structural model we call the Convergent Skills Model of Reading Development. Although previous studies provided piecemeal evidence for many of these relationships, none have assessed the particular configuration of those specified by the model. Results from the study provide initial support for the Convergent Skills Model in terms of both the links between the components of reading ability included in the model and developmental differences in the weights assigned to these components as determinants of reading ability. This support comes from several findings. First, the model produced statistically significant and robust fit indexes in both the Younger and Older reader groups, suggesting that it is theoretically viable. Second, most of the path coefficients for the hypothesized causal relationships specified by the model were found to be statistically significant. Third, the model generated a pattern of results that accords quite well with our assumption that visual abilities are largely mediated by language-based abilities, especially phonological abilities, as determinants of reading skill acquisition. Fourth, the model accounted for substantial amounts of variance in all of the reading subskills and in most of the reading-related cognitive abilities in both reader groups.

Finally, our data extend and complement previous research findings insofar as relationships between word identification and related phonological skills on the one hand and reading comprehension on the other were found to be stronger and 
statistically more stable in the Younger group than in the Older group, whereas relationships between language comprehension skills and reading comprehension tended to be stronger in the older than in the younger group (Curtis, 1980; Hoover \& Gough, 1990; Sticht, 1979; Vellutino et al., 1991; Vellutino et al., 1994). Note, however, that because our test battery did not include a measure of timed word identification, our findings do not exclude the possibility that such a measure would have contributed significant variance to reading comprehension in the older as well as in the younger group (e.g., see Carver, 1998), given the importance of reading fluency to reading comprehension (Perfetti, 1985). Yet, the results do make it clear that language comprehension becomes the dominant process in reading comprehension when the reader has acquired enough facility in word identification to comprehend in written language text which would normally be comprehended in spoken language, as we contended earlier. Thus these data can be taken as additional confirmation for Sticht's (1979) Audread model and Gough and Tunmer's (1986) Simple View model and are quite in keeping with similar conceptualizations of reading development forwarded by other theorists (Carver, 1998; Ehri, 1991; Liberman \& Liberman, 1990; Perfetti, 1985; Stanovich, 1991).

However, results are contrary to our expectation that semantic and syntactic skills would be more important determinants of reading ability in more proficient readers than in less proficient readers insofar as the path coefficients for the total effect of Semantic Knowledge on Reading Comprehension were found to be statistically significant and rather robust in both the Younger and Older reader groups, whereas the path coefficients for the total effect of Syntactic Knowledge on Reading Comprehension did not achieve statistical significance in either group. The finding of equally strong effects of Semantic Knowledge in both reader groups suggests that vocabulary and other types of semantic knowledge are important determinants of language and reading comprehension skills in early and late-stage readers, though this relationship was somewhat stronger in late-stage readers. Yet, because language comprehension processes tend to make heavier demands on semantic knowledge in late-stage readers, we fully expected that the Semantic Knowledge component of our model would be more strongly related to Language and Reading Comprehension in the Older reader group than in the Younger reader group. The reason(s) this expectation was not realized is not altogether clear, but one possible reason is that overrepresentation of children in the extreme ranges of reading ability (as discussed earlier) may have inflated correlations among the observed measures used to operationally define Semantic Knowledge, Language Comprehension, and Reading Comprehension more so in the Younger than in the Older group because of the much larger number of children in the Younger group. This circumstance may have served to distill the magnitude of group differences in the paths connecting Semantic Knowledge and Language Comprehension and thereby group differences in the total effect of Semantic Knowledge on Reading 
Comprehension. Thus the hypothesis as originally articulated remains viable and is worthy of continued research.

As regards the absence of any effects of Syntactic Knowledge on Language and Reading Comprehension, we suggested earlier that this finding may have been partly due to common variance shared with Semantic Knowledge and Language Comprehension, and we obtained some support for this possibility in additional analyses. Specifically, we found that eliminating the causal path between Semantic Knowledge and Syntactic Knowledge produced a significant coefficient for the path between Syntactic Knowledge and Language Comprehension in the Younger group and an unacceptable model in the Older group, whereas eliminating the path between Semantic Knowledge and Language Comprehension produced an unacceptable model in the Younger group and a significant coefficient for the path between Syntactic Knowledge and Language Comprehension in the Older group. Thus both paths would appear to be important components of the model. Note, however, that our findings should not be interpreted as an indication that Syntactic Knowledge does not contribute unique variance to Language Comprehension because a more direct measure of this construct (e.g., sentence comprehension) would likely be found to be more strongly related to Language Comprehension than was the syntactic awareness test we used to define the construct, as we suggested in a previous section.

Because of the absence of significant differences between the Older and Younger groups in the contribution made by Semantic Knowledge to Language and Reading Comprehension and because Syntactic Knowledge did not contribute significant variance to Language and Reading Comprehension in either group, a question that naturally arises is what factors, in addition to increased facility in Context-Free Word Identification, could account for the finding that Language Comprehension contributed significantly more variance to Reading Comprehension in the Older than in the Younger group. One obvious factor could be syntactic competence of the type not adequately assessed by the test used to define Syntactic Knowledge, as we have just indicated. Other likely factors may include comprehension processes and strategies known to be more effectively implemented in older than in younger readers but not assessed by our test battery, for example, activation of background knowledge, comprehension monitoring, critical analysis, and use of inference to name a few. Given that our model explained less variance in Language Comprehension in the Older than in the Younger group (see Table 4), this explanation of the disparity in question seems plausible.

As for the finding that a few coefficients other than those involving Syntactic Knowledge did not achieve statistical significance, we observed in additional analyses evaluating alternative versions of the model that these outcomes, in several instances, were due to shared variance absorbed by given constructs, as with some of the causal relationships involving Syntactic Knowledge. In addition to imperfect measurement, such outcomes may well signify the need to consider modified ver- 
sions of the model in both the Younger and Older groups, for example, eliminating causal paths that did not survive the bootstrapping procedure as well as those that were not statistically significant before bootstrapping. In fact, the results suggest that some latent constructs incorporated in the model are only weakly related in the populations from which our samples were drawn and that others are indirectly rather than directly related. For example, most path coefficients that did not survive the bootstrapping procedure in the Older group were associated with relationships between constructs entailed in acquiring basic word-level skills, but this was not found to be the case in the Younger group, suggesting that such abilities are more weakly related in older readers than in younger readers, as we hypothesized. Similarly, the failure to obtain a significant coefficient for the direct effect of Phonological Coding on Context-Free Word Identification in the Younger as well as in the Older reader groups suggests that the relationship between these constructs is mediated by Phonological Awareness, Spelling, and Phonological Decoding, as we pointed out earlier. Such possibilities need to be further evaluated in future research, but because the Convergent Skills Model, as originally specified, produced better fit statistics than modified versions of the model, we suggest that the original version provides a plausible account of the relationships among the major components of reading ability in both early and late-stage readers.

Despite the fact that visual abilities were only weakly related to word-level skills in both developmental groups, one cannot rule out the contribution of visual abilities altogether because Visual Coding and Visual Analysis were found to have significant direct and/or indirect effects on Spelling, Context-Free Word Identification, Phonological Awareness, and Semantic Knowledge in both the Younger and Older groups. Note, however, that none of the word-level visual effects survived the bootstrapping procedure in the Older group, but all did so in the Younger group, in accord with our expectation that word-level effects would be stronger in younger readers than in older readers. That Visual Analysis was found to be directly related to Phonological Awareness may appear to some to be anomalous, given that phoneme analysis, by definition, is an auditory processing task. However, "overshoot" errors (counting letters rather than phonemes) are commonly observed in developing readers on phoneme counting tasks (e.g., Tunmer \& Nesdale, 1985), and this along with other findings (Rack, 1985; Zecker, 1991) suggests that orthographic images are often activated during the course of processing spoken words and may influence analysis of those words on phoneme segmentation tasks. If so, then the finding of a direct causal relationship between Visual Analysis and Phoneme Awareness becomes coherent.

Finally, it seems important to underscore certain limitations in this study. One limitation is that some of the observed measures used to define given constructs may not have been ideal measures of those constructs, as we have already suggested. This situation was, no doubt, complicated by the fact that we were unable to use only a single measure to define some of the constructs. A second is that the 
data used to evaluate the Convergent Skills Model are cross-sectional in nature. Thus it was not possible to assess either the time course of developmental changes in hypothesized relationships specified by the model or the type of reciprocity that often defines the relationship between given constructs, whereby growth in one facilitates growth in the other over time, for example, the relationship between Phonological Awareness and Context-Free Word Identification, which has been shown to be distinctly reciprocal in longitudinal research (e.g., Perfetti, Beck, Bell, \& Hughes, 1987). A third limitation is that our model did not include constructs representing the precursors of early reading achievement. Because the youngest children in our sample were second graders rather than kindergartners or preschoolers, we were unable to evaluate the contribution made by emergent literacy skills, such as knowledge of print concepts (e.g., words consist of letters, letters carry sound values, etc.), sensitivity to rhyme, and knowledge of the alphabet, to early and later literacy development (e.g., see Lonigan et al., 2000; Storch \& Whitehurst, 2002). Thus it remains to be seen whether our findings will be cross-validated in longitudinal research that can assess both emergent literacy effects and reciprocity effects as determinants of literacy development.

A final limitation of this study is that the method of sample selection used in evaluating the Convergent Skills Model may limit the external validity of our results as well as the accuracy of the parameter estimates and their corresponding standard errors. Although the full range of reading abilities was represented by the reading measure used to select children at the two age/grade levels of interest in this study, the number of participants in given ranges was somewhat greater than the number expected on the assumption of normality, which could produce inflated parameter estimates. Thus the model must be viewed as tentative. However, it is important to remind the reader that the bootstrapping procedure we used to assess the stability of parameter estimates compensates to some extent for nonnormality in the distributions generated by observed measures, and we can therefore have some degree of confidence in at least those estimates that survived this procedure.

A few concluding remarks seem in order. Although our interpretations of the present findings are consistent with the model we specified, we fully recognize that there may be alternative models that can equally account for the data and lead to somewhat different interpretations. However, we believe we provided sound theoretical arguments for each of the proposed linkages in the model, supporting each linkage with references to existing literature concerned with the study of reading development. Moreover, given the number of latent constructs included in our model, the number of logically possible models that we could test against ours would be extremely large, and it was not possible to test them all. We did, however, assess several logical variants of our model (e.g., Phonological Decoding "causing" Spelling; Semantic Knowledge "causing" Spelling) and found that ours produced a better fit to the observed data than did these other models. Thus we believe that results generated by the Convergent Skills Model make a significant contribu- 
tion to the extant literature. It remains for other researchers to specify and assess alternative models we did not assess.

\section{ACKNOWLEDGMENTS}

The research reported in this article was supported by a grant from the National Institute of Child Health and Human Development (\#R01HD09658) to the Child Research and Study Center at the University at Albany (Frank R. Vellutino and Donna M. Scanlon, Co-Investigators). We thank the students, teachers, and administrators who so graciously participated in or facilitated this research. We also thank Donna Scanlon for reading and commenting on an early draft of this article. Thanks are due, as well, to the many members of our research staff and students who were responsible for collecting and collating the data and assisting in manuscript preparation, especially Sheila Small, Diane Fanuele, Yoonok Kim, and Haiyan Zhang.

\section{REFERENCES}

Arbuckle, J. L. (1997). AMOS users' guide: Version 3.6. Chicago: SPSS Inc.

Baddeley, A. D. (1986). Working memory. Oxford, UK: Oxford University Press.

Blachman, B. A. (2000). Phonological awareness. In M. L. Kamil, P. B. Mosenthal, P. D. Pearson, \& R. Barr (Eds.), Handbook of reading research (Vol. 3, pp. 483-502). Hillsdale, NJ: Lawrence Erlbaum Associates, Inc.

Bradley, L., \& Bryant, P. E. (1983). Categorizing sounds and learning to read-A causal connection. Nature, 303, 419-421.

Calfee, R. C., \& Calfee, K. H. (1981). Interactive Reading Assessment System. Unpublished manuscript, Stanford University, Stanford, CA.

Carver, R. (1998). Predicting reading level in grades 1 to 6 from listening level and decoding level: Testing theory relevant to the simple view of reading. Reading and Writing: An Interdisciplinary Journal, 10, 121-154.

Curtis, M. E. (1980). Development of components of reading skill. Journal of Educational Psychology, 72, 656-669.

Effron, B., \& Tibishirani, R. (1993). An introduction to bootstrapping. New York: Chapman \& Hall.

Ehri, L. (1991). Development of the ability to read words. In R. Barr, M. Kamil, P. Mosenthal, \& P. D. Pearson (Eds.), Handbook of reading research (Vol. 2, pp. 384-417). New York: Longman.

Frith, U. (1985). Beneath the surface of developmental dyslexia. In K. E. Patterson, J. C. Marshall, \& M. Coltheart (Eds.), Surface dyslexia (pp. 301-330). Hillsdale, NJ: Lawrence Erlbaum Associates, Inc.

Gathercole, S. E., \& Baddeley, A. D. (1989). Evaluation of the role of phonological STM in the development of vocabulary in children: A longitudinal study. Journal of Memory \& Language, 28, 200-213.

Gathercole, S. E., \& Baddeley, A. D. (1990). The role of phonological memory in vocabulary acquisition: A study of young children learning new names. British Journal of Psychology, 81, 455-468.

Gilmore, J. V., \& Gilmore, E. C. (1968). Gilmore Oral Reading Test. New York: Harcourt Brace. 
Goff, D. A., Pratt, C., \& Ong, B. (2005). The relations between children's reading comprehension, working memory, language skills, and components of reading decoding in a normal sample. Reading and Writing, 18, 583-616.

Gough, P. B., \& Tunmer, W. E. (1986). Decoding, reading, and reading disability. Remedial and Special Education, 7, 6-10.

Harris, A. J., \& Jacobson, M. D. (1982). Basic reading vocabularies. New York: Macmillan.

Henderson, E. H. (1990). Teaching spelling. Boston: Houghton Mifflin.

Hoover, W., \& Gough, P. B. (1990). The simple view of reading. Reading and Writing: An Interdisciplinary Journal, 2, 127-160.

Iversen, S., \& Tunmer, W. (1993). Phonological processing skills and the reading recovery program. Journal of Educational Psychology, 85, 112-126.

Jaccard, J., Turrisi, R., \& Wan, C. K. (1990). Interaction effects in multiple regression. Newbury Park, CA: Sage.

Jaccard, J., \& Wan, C. K. (1996). LISREL analyses of interaction effects in multiple regression. Newbury Park, CA: Sage.

Jöreskog, K. G., \& Sörbom, D. (1993a). LISREL 7: A guide to the program and application (2nd ed.). Chicago: SPSS Inc.

Jöreskog, K. G., \& Sörbom, D. (1993b). LISREL 8: Structural equation modeling with the SIMPIIS command language. Hillsdale, NJ: Lawrence Erlbaum Associates, Inc.

Larsen, S. C., \& Hammill, D. D. (1986). Test of Written Spelling. Austin, TX: PRO-ED.

Liberman, I. Y., \& Liberman, A. M. (1990). Whole language vs. code emphasis: Underlying assumptions and their implications for reading instruction. Annals of Dyslexia, 40, 51-76.

Liberman, I. Y., \& Shankweiler, D. (1990). Speech, the alphabet, and teaching to read. In L. B. Resnick \& P. A. Weaver (Eds.), Theory and practice of early reading (Vol. 2, pp. 109-132). Hillsdale, NJ: Lawrence Erlbaum Associates, Inc.

Lonigan, C. J., Burgess, S. R., \& Anthony, J. L. (2000). Development of emergent literacy and early reading skills in pre-school children: Evidence from a latent variable longitudinal study. Developmental Psychology, 36, 596-613.

Perfetti, C. A. (1985). Reading ability. New York: Oxford University Press.

Perfetti, C. A., Beck, I., Bell, L., \& Hughes, C. (1987). Phonemic knowledge and learning to read are reciprocal: A longitudinal study of first grade children. Merrill Palmer Quarterly, 33, 283-319.

Rack, J. P. (1985). Orthographic and phonetic coding in developmental dyslexia. British Journal of Psychology, 76, 325-340.

Seigneuric, A., \& Ehrlich, M. (2005). Contribution of working memory capacity to children's reading comprehension: A longitudinal investigation. Reading and Writing, 18, 617-656.

Share, D. L. (1995). Phonological coding and self-teaching: Sine qua non of reading acquisition. Cognition, 55, 151-218.

Spache, G. D. (1981). Diagnostic Reading Scales. Monterey, CA: McGraw-Hill.

Stanovich, K. E. (1991). Word recognition: Changing perspectives. In R. Barr, M. L. Kamil, P. Mosenthal, \& P. D. Pearson (Eds.), Handbook of reading research (Vol. 2, pp. 418-452). New York: Longman.

Sticht, T. G. (1979). Applications of the Audread model to reading evaluation and instruction. In L. B. Resnick \& P. A. Weaver (Eds.), Theory and practice of early reading (Vol. 1, pp. 209-226). Hillsdale, NJ: Lawrence Erlbaum Associates, Inc.

Storch, S. A., \& Whitehurst, G. J. (2002). Oral-language and code-related precursors to reading: Evidence from a longitudinal structural model. Developmental Psychology, 38, 934-937.

Templeton, S. (1995). Children's literacy. Boston: Houghton Mifflin.

Torgesen, J. K., Wagner, R. K., \& Rashotte, C. A. (1999). Preventing reading failure in young children with phonological processing disabilities: Group and individual responses to instruction. Journal of Educational Psychology, 91, 579-594. 
Tunmer, W. E. (1989). The role of language related factors in reading disability. In D. Shankweiler \& I. Y. Liberman (Eds.), Phonology and reading disability: Solving the reading puzzle (pp. 91-131). Ann Arbor: University of Michigan Press.

Tunmer, W. E., \& Chapman, J. (1998). Language prediction skill, phonological recoding ability, and beginning reading. In C. Hulme \& R. M. Joshi (Eds.), Reading and spelling: Development and disor$\operatorname{der}$ (pp. 33-67). Mahwah, NJ: Lawrence Erlbaum Associates, Inc.

Tunmer, W. E., \& Chapman, J. W. (2006). Metalinguistic abilities, phonological recoding skill, and the use of context in beginning reading development: A longitudinal study. In R. M. Joshi \& P. G. Aaron (Eds.), Handbook of orthography and literacy (pp. 617-635). Mahwah, NJ: Lawrence Erlbaum Associates, Inc.

Tunmer, W. E., \& Nesdale, A. R. (1985). Phonemic segmentation skill and beginning reading. Journal of Educational Psychology, 77, 417-427.

Tunmer, W. E., Nesdale, A. R., \& Wright, A. D. (1987). Syntactic awareness and reading acquisition. British Journal of Developmental Psychology, 5, 305-322.

Vellutino, F. R. (1979). Dyslexia: Theory and research. Cambridge, MA: MIT Press.

Vellutino, F. R., Fletcher, J. M., Snowling, M. J., \& Scanlon, D. M. (2004). Specific reading disability (dyslexia): What have we learned in the past four decades? Journal of Child Psychology and Psychiatry, 45(1), 2-40.

Vellutino, F. R., \& Scanlon, D. M. (1987a). Linguistic coding and reading ability. In S. Rosenberg (Ed.), Advances in applied psycholinguistics (Vol. 1, pp. 1-69). New York: Cambridge University Press.

Vellutino, F. R., \& Scanlon, D. M. (1987b). Phonological coding, phonological awareness, and reading ability: Evidence from a longitudinal and experimental study. Merrill Palmer Quarterly, 33, 321-363.

Vellutino, F. R., Scanlon, D. M., \& Chen, R. S. (1995). The inextricable relationship between orthographic and phonological coding in learning to read: Some reservations about current methods of operationalizing orthographic coding. In V. W. Berninger (Ed.), The varieties of orthographic knowledge: Vol. 2. Relationships to phonology, reading, and writing (pp. 47-111). Norwell, MA: Kluwer Academic.

Vellutino, F. R., Scanlon, D. M., Sipay, E. R., Small, S. G., Pratt, A., Chen, R., et al. (1996). Cognitive profiles of difficult to remediate and readily remediated poor readers: Early intervention as a vehicle for distinguishing between cognitive and experiential deficits as basic causes of specific reading disability. Journal of Educational Psychology, 88, 601-638.

Vellutino, F. R., Scanlon, D. M., Small, S. G., \& Tanzman, M. S. (1991). The linguistic basis of reading ability: Converting written to oral language. Text, 11, 99-133.

Vellutino, F. R., Scanlon, D. M., \& Tanzman, M. S. (1994). Components of reading ability: Issues and problems in operationalizing word identification, phonological coding, and orthographic coding. In G. R. Lyon (Ed.), Frames of reference for the assessment of learning disabilities: New views on measurement issues (pp. 279-329). Baltimore: Brookes.

Wagner, R. K., \& Torgesen, J. K. (1987). The nature of phonological processing and its causal role in the acquisition of reading skills. Psychological Bulletin, 101, 192-212.

Wechsler, D. (1974). Wechsler Intelligence Scale for Children-Revised. New York: Psychological Corporation.

Woodcock, R. W., \& Johnson, M. D. (1977). Woodcock-Johnson Psycho-Educational Battery. Boston: Teaching Resources Corporation.

Zecker, S. G. (1991). The orthographic code: Developmental trends in reading disabled and normally achieving children. Annals of Dyslexia, 41, 178-192.

Manuscript received June 23, 2003

Accepted December 19, 2005 